\title{
A Comparative Study on the Lingual Tonsil in Goats and Pigs
}

\author{
V. R. Indu ${ }^{\text {** }}$ K. M. Lucy ${ }^{2}$, K. S. Prashanth Kumar ${ }^{3}$, N. Ashok ${ }^{4}$ and S. Maya ${ }^{1}$ \\ ${ }^{1}$ Department of Veterinary Anatomy, College of Veterinary and Animal Sciences, \\ Mannuthy - 680651, Kerala, India \\ ${ }^{2}$ Controller of Examinations, Kerala Veterinary and Animal Sciences University, \\ Pookode-673 576, India \\ ${ }^{3}$ Veterinary Officer, Veterinary Dispensary, Belludi, Davangere, Karnataka, India \\ ${ }^{4}$ Director (Academics \& Research), Kerala Veterinary and Animal Sciences University, \\ Pookode-673 576, India \\ *Corresponding author
}

\begin{abstract}
A B S T R A C T

\begin{tabular}{|l|}
\hline Key w or d s \\
Pigs, Goats, \\
Histology, \\
Morphology, \\
Lingual tonsil \\
\hline Article Info \\
\hline $\begin{array}{l}\text { Accepted: } \\
\text { 24 May } 2018 \\
\text { Available Online: } \\
\text { 10 June 2018 }\end{array}$ \\
\hline \hline
\end{tabular}

A study was conducted on the lingual tonsil of six adult male crossbred goats and Large White Yorkshire pigs. The lingual tonsil could not be identified macroscopically but in histological sections aggregations of lymphocytes were seen within the core of mechanical conical papillae in pigs and vallate papillae in goats. The stratified squamous surface epithelium of lingual tonsil was keratinized in goats while non-keratinized in pigs. At the region of crypts, the surface epithelium consisted of few cell layers associated with numerous lymphocytes and was called as reticular epithelium or lymphoepithelium. Hassall's corpuscles were occasionally detected towards the outer surface epithelium. Propria-submucosa in the core of conical papillae in pigs presented numerous lymphatic nodules of different shapes and dimensions and were separated from the surrounding adipose tissue and glands by a dense connective tissue capsule. However in goats the lymphoid accumulation in vallate papillae was devoid of any lymphatic nodules and was not encapsulated. Lymphoid cell aggregations were also noticed in between glandular acini, striated muscles and around the ducts of mucous glands which opened towards the surface epithelium of the vallate papillae.
\end{abstract}

\section{Introduction}

According to Nickel et al., (1979), diffuse lymphocytic accumulations in the tongue of domestic animals were grouped under tonsillar tissue. The lingual tonsil was limited to the root of the tongue in sheeps (Cocquyt et al., 2005), horses (Kumar and Timoney, 2005) and bovines (Cocquyt et al., 2008). This tonsil is involved in processing antigens because of its close association with diffuse lymphoid tissue and high endothelial venules, making it the first line of defense.

A perusal of literature revealed only few studies on the comparative studies of the lingual tonsils in goats and pigs, hence the present work was undertaken. 


\section{Materials and Methods}

A study was undertaken to compare the histomorphology and histochemistry of the lingual tonsil in indigenous pigs of Kerala and crossbred goats. Tissue samples were collected from six apparently healthy adult male goats and pigs sold for slaughter from University Sheep and Goat Farm, Mannuthy and Centre for Pig Production and Research, Mannuthy respectively. From median sections of the head, tissue pieces were collected from the tongue and fixed in 10 per cent neutral buffered formalin. The materials were processed routinely to obtain $5-6 \mu \mathrm{m}$ thick serial paraffin sections. The sections were stained by Haematoxylin and Eosin (Luna, 1968), Gomori's rapid one step trichrome method for collagen fibres (Luna, 1968), Verhoeff's method for elastic fibres (Singh and Sulochana, 1996), Gordon and Sweet's method for reticular fibres (Bancroft and Gamble, 2003) and Unna's method for mast cells (Luna, 1968).

\section{Results and Discussion}

The lingual tonsils were not visible macroscopically in both pigs and goats. In histological sections they could be seen at the root of the tongue within the connective tissue cores of the mechanical conical papillae in pigs and in the vallate papillae in goats (Fig.1\&2). Casteleyn et al., (2011) concluded that the lingual tonsils were more prominent in pigs compared to small ruminants but less developed compared to ox.

The lingual tonsils in pigs were lined by a non-keratinized stratified squamous surface epithelium however in goats it was keratinised (Fig.3\&4). The epithelium was composed of stratum basale, stratum spinosum and stratum superficiale in both the species. The columnar cells of stratum basale presented oval to elongated nuclei that was strongly basophilic and the cytoplasm was slightly basophilic. In the stratum spinosum, six to twelve layers of irregularly polyhedral cells were seen with lightly basophilic nuclei of different shapes. The stratum superficiale consisted of squamous cells with eosinophilic and finely granular cytoplasm and irregular pyknotic nuclei.

The signs of degeneration in the nuclei were more towards the free surface of the epithelium. However in goats keratohyaline granules were seen in the stratum superficiale and hence it was referred to as stratum corneum. The presence of keratohyaline granules in the stratum superficiale was reported in the lingual tonsil in horse by Kumar and Timoney (2005) and in goat by Kumar and Kumar (2005).

The surface epithelium in both the species studied had an irregular outer surface and an unevenly placed deeper surface which extended into the lamina propria mucosa as interpapillary pegs. Lamellated structures resembling Hassall's corpuscles were observed towards the outer surface epithelium. These observations concur with the earlier reports of Kumar and Timoney (2005) in horse and Kumar and Kumar (2005) in goat. Degeneration of epithelial cells and formation of epithelial corpuscles was associated with reticulation of tonsillar and thymic epithelium (Perry and Slipka, 1993).

In the present work it was noticed that the stratified squamous surface epithelium of the tonsil in both the species continued into the crypts as crypt epithelium with some lymphoid cell infiltration and was referred to as reticular epithelium or lymphoepithelium. In this epithelium the stratum spinosum and superficiale were indistinguishable, interpapillary pegs were lacking and lymphoid tissue infiltration occurred forming a lymphoepithelial symbiosis. 
Fig.1 C.S. of vallate papillae of goat showing lymphoid aggregations. H\&Ex200

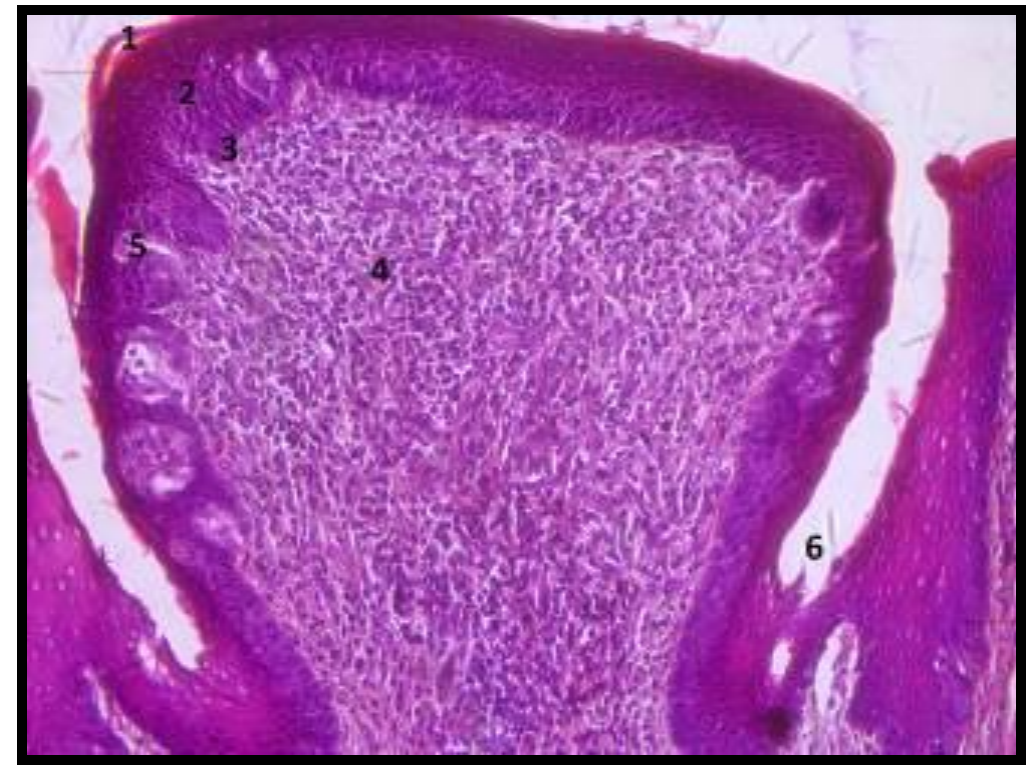

1. Stratum corneum

2. Stratum spinosum

3. Stratum basale

4. Lymphocytes in connective tissue core

5. Taste bud

6. Crypt

Fig.2 C.S. of conical papillae of pig showing lymphoid aggregations. H\&Ex200

1. Stratum superficiale



2. Stratum spinosum

3. Stratum basale

4. Lymphoid nodules in connective tissue core 
Fig.3 C.S. of lingual tonsil of goat showing keratinized epithelium. Ayoub-Shklar method X 100

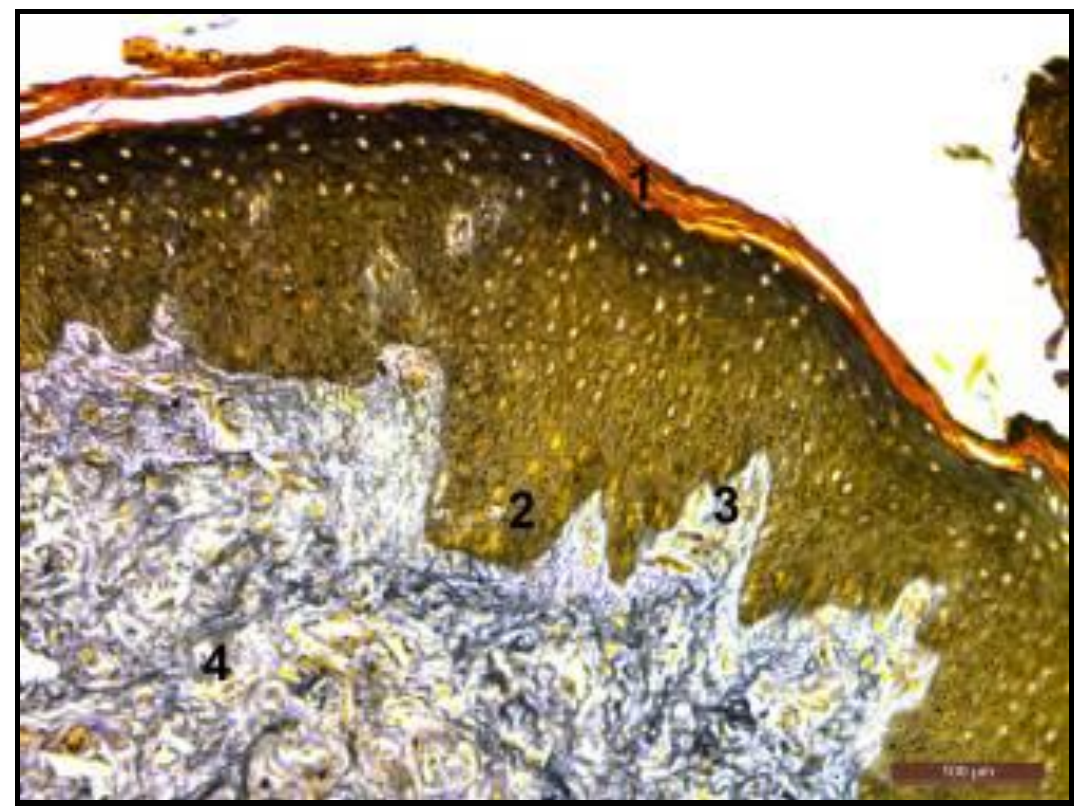

1. Keratinized stratified squamous epithelium

2. Pegs

3. Papillae

4. Connective tissue core

Fig.4 C.S. of lingual tonsil of pig showing non-keratinized epithelium. Ayoub-Shklar method X 100

1. Non-keratinized stratified squamous epithelium

2. Pegs

3. Papillae

4. Lymphoid nodules 
Fig.5 C.S. of lingual tonsil of pig showing tonsillar nodule. H\&E x 100

1. Lymphoid nodule

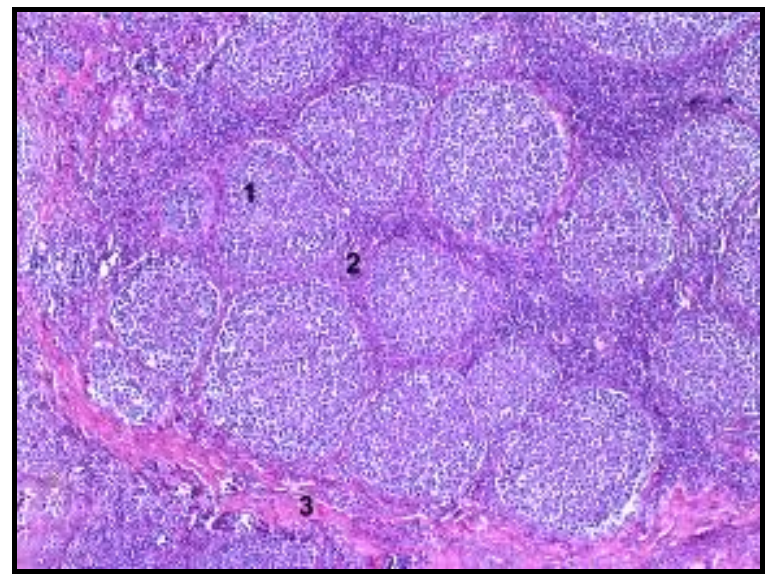

2. Internodular connective tissue

3. Capsule

Fig.6 C.S. of lingual tonsil of pig showing tonsillar follicle. Gomori's one step trichrome x100

1. Crypt

2. Reticular epithelium

3. Lymphoid nodule

4. Parafollicular area

5. Interfollicular area

6. Capsule

The close association between the lumen of the crypt and the internal milieu of the tonsil provided an important role for tonsils in the immunological response against antigens which entered the body by oral route.Similar observations were recorded by Kumar and
Kumar (2005) in goats, Kumar and Timoney (2005) in horse and by Casteleyn et al., (2011) in pigs.

The lamina propria of the tonsil was characterized by dense irregular connective, 
lymphoid, glandular, adipose and muscular tissues in both pigs and goats. In the superficial part of lamina propria dense irregular connective tissue papillae extended into the surface epithelium between the interpapillary pegs. The reticular fibres formed a uniform basement membrane at the base of the outer surface epithelium. However at the areas of reticular epithelium due to heavy infiltration of lymphocytes the basement membrane was fragmented, collagen fibres decreased and the number of blood capillaries increased. These observations were in accordance with the findings of Kumar and Timoney (2005) in horse and Kumar and Kumar (2005) in goats.

It was observed that in the deeper part of lamina propria distribution of lymphoid tissue differed in pigs and goats. In lingual tonsil of pigs the lymphoid tissue was distributed in the form of diffuse accumulation of lymphocytes and numerous lymphatic nodules of different shapes and dimensions. Some of the nodules presented darker outer corona and inner germinal centre. The lymphatic nodules organized in aggregations and encapsulated by connective tissue surrounding an epithelial crypt were called cryptolymphatic units (CLU) or tonsillar follicles and those without crypts were called tonsillar nodules (Fig. 5\&6). The lymphatic nodules were separated by parafollicular and interfollicular areas composed of a dense meshwork of reticular a few collagen and elastic fibres. The interfollicular areas were populated with small, medium and large lymphocytes, plasma cells, macrophages, blood capillaries and high endothelial venules (HEVs). Similar distribution of lymphoid tissue was seen in the conical papillae of pigs by Schaller (1992) and Casteleyn et al., (2011).

However in goats only a few small crypts were seen where the surface epithelium was modified into reticular epithelium or lymphoepithelium and was associated with lymphocytes. In the core of vallate papillae a small meshwork of reticular fibres was seen with a few lymphoid cells. The lymphoid tissue was devoid of any lymphoid nodules and was not encapsulated (Fig.6). These observations agreed with the findings of Kumar and Kumar (2005) in goats.

Numerous fine blood capillaries and high endothelial venules (HEVs) were also noted in the lamina propria. Ruskell (1995) found that transfer of lymphocytes from the blood to the tonsils was essential for their immunological capability but since the tonsils lacked afferent lymphatics naive lymphocytes entered through specific blood vessels known as HEVs.

In both the species of animals studied deeper part of propria-submucosa presented both serous and mucous glands, bundles of skeletal muscle, nerve bundles and adipose tissue. Lymphoid cell aggregations were also noticed in between glandular acini, ducts of mucous glands which opened towards the surface epithelium and in between bundles of striated muscles. These observations agreed with the findings of Kumar and Timoney (2005) in horse and Kumar and Kumar (2005) in goats.

It was concluded that the lingual tonsil was well developed in pigs as compared to the goats to offer better immunological protection at the entrance of the digestive system as it is an omnivore with diverse feeding habits.

\section{References}

Bancroft, J.D. and Gamble, M. 2003. Theory and Practice of Histological Techniques. $\quad\left(5^{\text {th }}\right.$ Ed.). Churchill Livingstone, New York, 796p.

Casteleyn, C., Breugelmans, S., Simoens, P. and Broeck, V.W. 2011. The tonsils revisited: Review of the anatomical 
localization and histological characteristics of the tonsils of domestic and laboratory animals. Clin. Dev. Immunol. 21: 1-14.

Cocquyt, G., Baten, T., Simoens, P. and Broeck, W.V.D. 2005. Anatomical localisation and histology of the ovine tonsils. Veterinary Immunology and Immunopathology. 107: 79-86.

Cocquyt, G., Simoens, P., Muylle, S. and Broeck, W. V. D. 2008. Anatomical and histological aspects of the bovine lingual tonsil. Research in Veterinary Science. 84: 166-173.

Kumar, P. and Kumar, P. 2005. Light and scanning electron microscopic studies on lingual tonsil of goat. Haryana Veterinarian. 44: 13-16.

Kumar, P. and Timoney, J.F. 2005b. Histology and ultrastructure of the equine lingual tonsil. I. crypt epithelium and associated structures. Anatomia Histologia Embryologia. 34: 27-33.
Luna, L.G. 1968. Manual of Histological Staining Methods of the Armed Forces Institute of Pathology. ( $3^{\text {rd }}$ Ed.). Mc Graw-Hill Book Company, New York, 258p.

Nickel, R., Schummer, A. and Seiferle, E. 1979. The Viscera of the Domestic Animals. Verlag Paul Parey, Berlin. 2202p.

Perry, M. E. and Slipka, J. 1993. Formation of the tonsillar corpuscle. Functional Developmental Morphology. 3: 165168.

Ruskell, G.L. 1995. Organization and cytology of lymphoid tissue in the cynomolgus monkey conjunctiva. Anatomical Record. 243: 153-164.

Schaller, O. 1992. Illustrated Veterinary Anatomical Nomenclature. ( $1^{\text {st }}$ Ed.). Stuttgart: Ferdinand Enke Verlag, 612p. Singh, U.B. and Sulochana, S. 1996. Handbook of Histological and Histochemical Techniques. Premier Publishing House, Hyderabad, 111p.

\section{How to cite this article:}

Indu V. R., K. M. Lucy, K. S. Prashanth Kumar, N. Ashok and Maya S. 2018. A Comparative Study on the Lingual Tonsil in Goats and Pigs. Int.J.Curr.Microbiol.App.Sci. 7(06): 3210-3216. doi: https://doi.org/10.20546/ijcmas.2018.706.377 